\title{
Updraft Model for Development of Autonomous Soaring Uninhabited Air Vehicles
}

\author{
Michael J. Allen* \\ NASA Dryden Flight Research Center, Edwards, California 93523-0273, USA
}

\begin{abstract}
Large birds and glider pilots commonly use updrafts caused by convection in the lower atmosphere to extend flight duration, increase cross-country speed, improve range, or simply to conserve energy. Uninhabited air vehicles may also have the ability to exploit updrafts to improve performance. An updraft model was developed at NASA Dryden Flight Research Center (Edwards, California) to investigate the use of convective lift for uninhabited air vehicles in desert regions. Balloon and surface measurements obtained at the National Oceanic and Atmospheric Administration Surface Radiation station (Desert Rock, Nevada) enabled the model development. The data were used to create a statistical representation of the convective velocity scale, $w^{*}$, and the convective mixing-layer thickness, $z_{i}$. These parameters were then used to determine updraft size, vertical velocity profile, spacing, and maximum height. This paper gives a complete description of the updraft model and its derivation. Computer code for running the model is also given in conjunction with a check case for model verification.
\end{abstract}

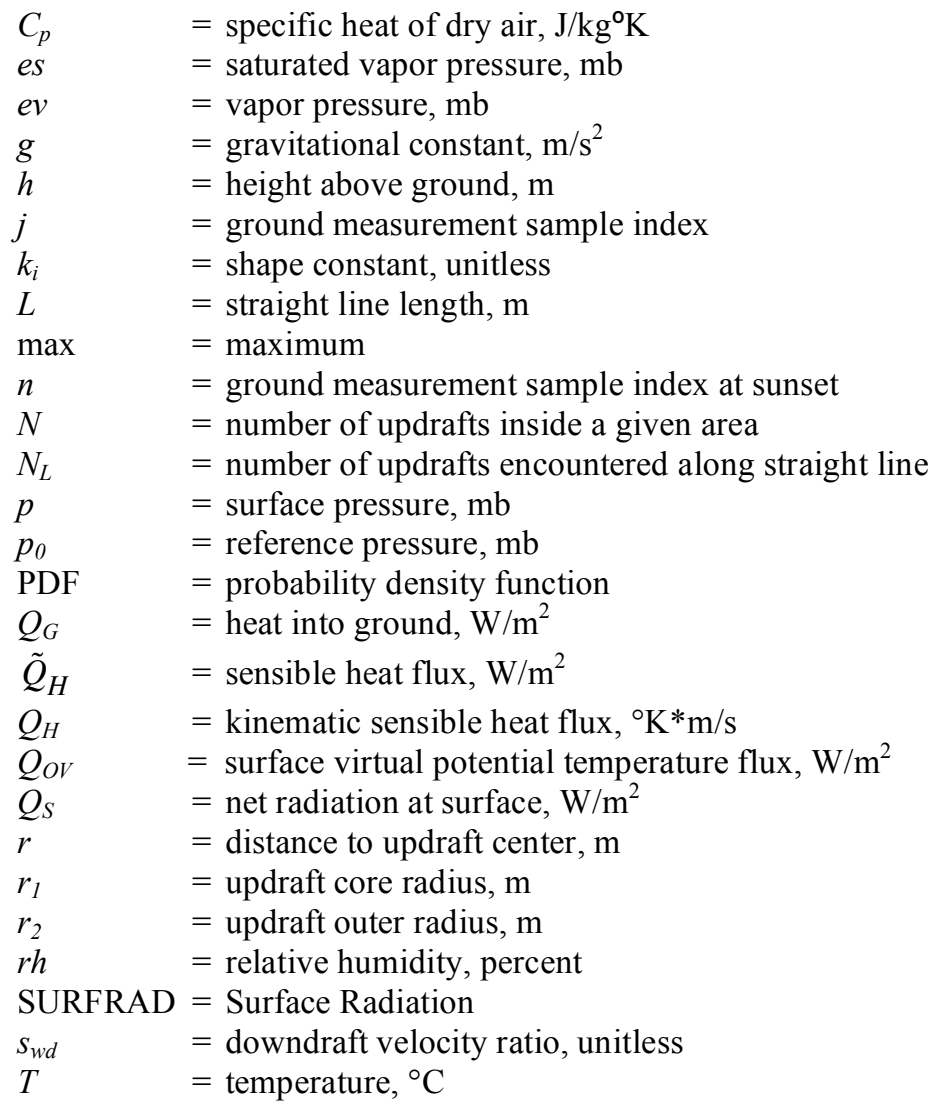

\footnotetext{
${ }^{*}$ Aerospace Engineer, Controls and Dynamics Branch, P.O. Box 273/MS-4840D, Member.
} 


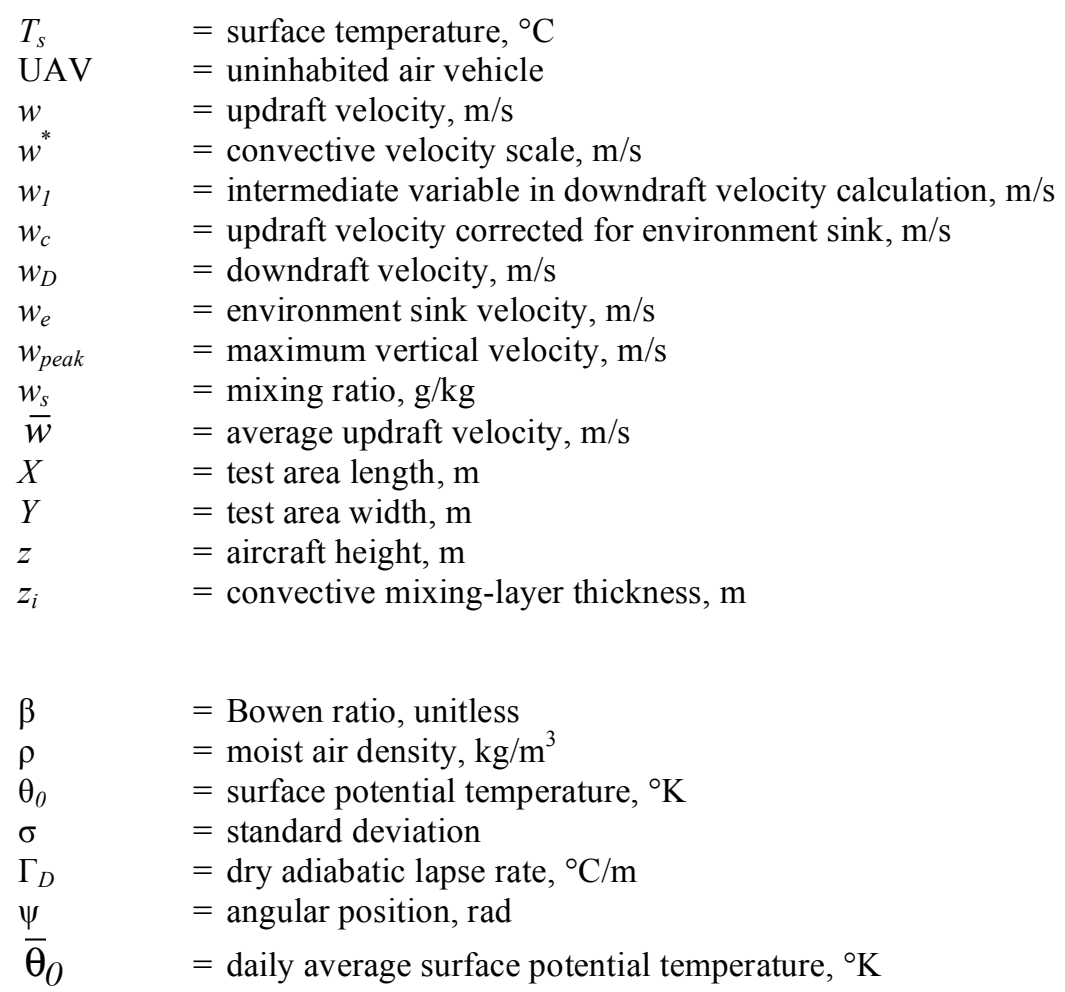

\section{Introduction}

$\mathrm{O}$ ne relatively unexplored way to improve the range, duration, or cross-country speed of an autonomous aircraft is to use buoyant plumes of air found in the lower atmosphere, known as thermals or updrafts. Updrafts occur when the air near the ground becomes less dense than the surrounding air because of heating or humidity changes at the surface of the Earth. Piloted sailplanes rely solely on this free energy to make flights of more than 2000 kilometers. ${ }^{1}$ Soaring birds such as hawks and vultures have been observed to circle for hours without flapping their wings; and Frigatebirds are known to soar continuously, day and night, using updrafts. ${ }^{2}$

Many uninhabited air vehicles (UAVs) have similar sizes, wing loadings, and missions as soaring birds and sailplanes. Such missions that could allow small UAVs to take advantage of updrafts encompass remote sensing, surveillance, atmospheric research, communications, and Earth science. A previous study using a simple UAV simulation with updrafts calculated from measured surface and balloon data found that a 2-hr nominalendurance UAV can potentially gain $12 \mathrm{hr}$ of flight time during the summer and $5 \mathrm{hr}$ of flight time during the winter using updrafts. ${ }^{3}$

Researchers have used various updraft models to study optimal soaring paths, ${ }^{4}$ glider design,${ }^{5}$ and cloud formation. ${ }^{6}$ Wharington used a simple updraft model to develop algorithms for a soaring UAV. ${ }^{7}$ These models generally provide a vertical velocity distribution for a given radius and peak updraft velocity. This paper presents a unique updraft model in that statistical values for updraft velocity, convective mixing-layer thickness, updraft spacing, and updraft size are determined from measured data.

\section{Convective-Layer Scale Factors}

The convective velocity scale, $w^{*}$, and convective mixing-layer thickness, $z_{i}$, were calculated from surface and rawinsonde balloon measurements taken at the National Oceanic and Atmospheric Administration (NOAA) Surface Radiation (SURFRAD) station in Desert Rock, Nevada (lat. $36.63 \mathrm{deg} \mathrm{N}$, long. $116.02 \mathrm{deg} \mathrm{W}$, elev. $1007 \mathrm{~m}$ ). The convective layer is the lowest region of the atmosphere where significant mixing occurs. During calm conditions, buoyant plumes of air that have been heated at the surface cause local mixing. These plumes of air, called updrafts or thermals, can have significant upward velocity.

SURFRAD instrumentation includes a radiometer platform, meteorology tower, and solar tracker. Measurements were taken every $3 \mathrm{~min}$. A rawinsonde station is also collocated with the SURFRAD site where rawinsonde balloons 
were launched every $12 \mathrm{hr}$. This study used surface temperature, wind, and radiation measurements as well as balloon-measured temperature and humidity collected from the entire year of $2002 .{ }^{8}$

The convective mixing-layer thickness, $z_{i}$, as Fig. 1 shows, is the maximum height-above-ground that updrafts generally obtain. The mixing-layer thickness was calculated using predawn rawinsonde balloon data and measured surface temperatures. The convective mixing-layer thickness was estimated by finding the intersection of the predawn balloon-measured temperature profile as a function of altitude with the line given by Eq. (1).

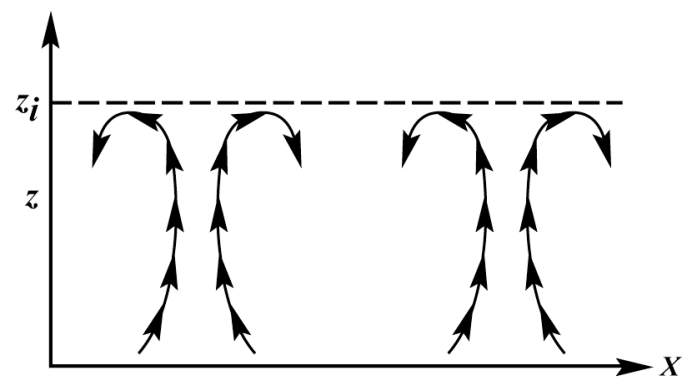

Figure 1. Simplified representation of atmosphere with updrafts showing convective mixing-layer thickness, $z_{i}$.

$$
T=-\Gamma_{D} h+T_{s}
$$

The line defined by Eq. (1) gives a temperature, $T$, for every height, $z$, using the dry adiabatic lapse rate, $\Gamma_{D}$, of $0.00975{ }^{\circ} \mathrm{C} / \mathrm{m}$. Figure 2 shows an example of the $z_{i}$ calculation.

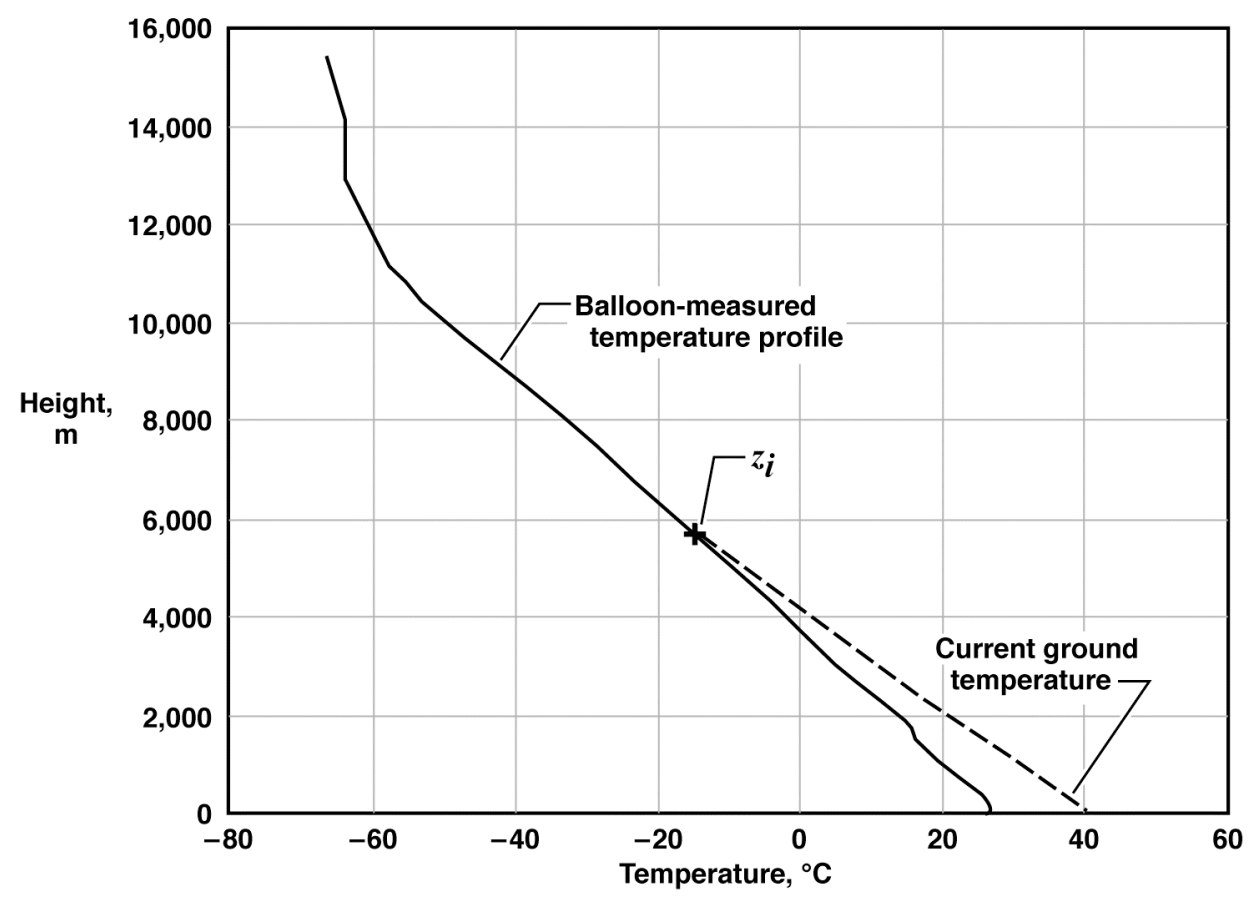

Figure 2. Example of $z_{i}$ calculation.

A surface heat budget was used to calculate the convective velocity scale, $w^{*}$. The first step in this process is to calculate the sensible heat flux, $\tilde{Q}_{H}$, given by Stull in Eq. (2). ${ }^{9}$ 


$$
\widetilde{Q}_{H}=\frac{\beta\left(-Q_{S}+Q_{G}\right)}{(1+\beta)}
$$

In this equation, $\tilde{Q}_{H}$ is the sensible heat flux, $Q_{S}$ is the net radiation at the surface, $Q_{G}$ is the heat into the ground, and $\beta$ is the Bowen ratio, defined as the ratio of sensible to latent heat fluxes at the surface. This study uses a Bowen ratio of 5, given for semi-arid regions. ${ }^{9}$ The net radiation, $Q_{S}$, was measured directly by the SURFRAD station; and the heat into the ground, $Q_{G}$, was calculated applying Eq. (3) taken from Stull ${ }^{9}$ using the percentage method for daytime calculations.

$$
Q_{G}=0.1 Q_{S}
$$

Sensible heat flux was then converted to its kinematic form using Eq. (4).

$$
Q_{H}=\frac{\tilde{Q}_{H}}{\rho C_{p}}
$$

Values for the density of moist air, $\rho$, and the specific heat of dry air, $C_{p}$, used in Eq. (4), were $1.210 \mathrm{~kg} / \mathrm{m}^{3}$ and $1004.67 \mathrm{~J} / \mathrm{kg}^{\circ} \mathrm{K}$, respectively. The surface virtual potential temperature flux, $Q_{O V}$, was then calculated with Eq. (5) using the definition of virtual potential temperature for unsaturated air. ${ }^{9}$

$$
Q_{O V}=Q_{H}\left(1+0.61 w_{s}\right)
$$

Equation (5) was solved using the mixing ratio, $w_{s}$, calculated from Eq. (6).

$$
w_{s}=\frac{622 e v}{p-e v}
$$

In Eq. (6), $p$ is the surface pressure and $e v$ is the vapor pressure given by Eq. (7).

$$
e v=r h \cdot e s / 100
$$

Equation (7) was solved using the measured relative humidity, $r h$, and saturated vapor pressure, es, calculated from Eq. (8).

$$
e s=6.112 e^{\frac{17.67 T_{s}}{T_{s}+243.5}}
$$

Equation (8) was solved using measured surface temperature, $T_{s}$. Equations (2) to (8) determine the surface heat budget required to calculate $Q_{O V}$. Equation (9) calculates the convective scaling velocity.

$$
w^{*}=\left(Q_{o v} z_{i} \frac{g}{\bar{\theta}_{0}}\right)^{\frac{1}{3}}
$$

In Eq. (9), $g$ is the gravitational constant and $\bar{\theta}_{0}$ is the daily average surface potential temperature given by Eq. (10). 


$$
\overline{\bar{\theta}}_{0}=\frac{\sum_{j=1}^{n}\left(T_{s_{j}}+273.15\right)\left(\frac{p_{0}}{p_{j}}\right)^{0.286}}{n}
$$

Equation (10) was solved using measured surface temperature, $T_{s,}$ and pressure, $p$, and a reference pressure, $p_{0}$, of $1000 \mathrm{mb}$. The sample index, $j=1$, refers to sunrise and $j=n$ refers to sunset. The convective velocity scale, $w^{*}$, is used primarily to calculate the updraft vertical velocity. The convective scale velocity was set to zero if the surface wind velocity was greater than $12.87 \mathrm{~m} / \mathrm{s}$ (25 knots) to account for the disruptive effect of high winds on updrafts.

\section{Test Point Matrix}

This study uses statistical tools to summarize yearly and daily changes in $z_{i}$ and $w^{*}$ into a set of representative cases. The histogram in Fig. 3 shows the distribution of $w^{*}$ for all daylight hours during the year 2002. Data points that produced a convective velocity scale of zero comprise 25 percent of the total set of recorded data and were not included in the Fig. 3 histogram. Zero convective mixing-layer thickness, zero net radiation, or high winds can cause zero scale velocity. Of these causes, the most prevalent was found to be zero net radiation because of low sun angles during early morning and late evening.

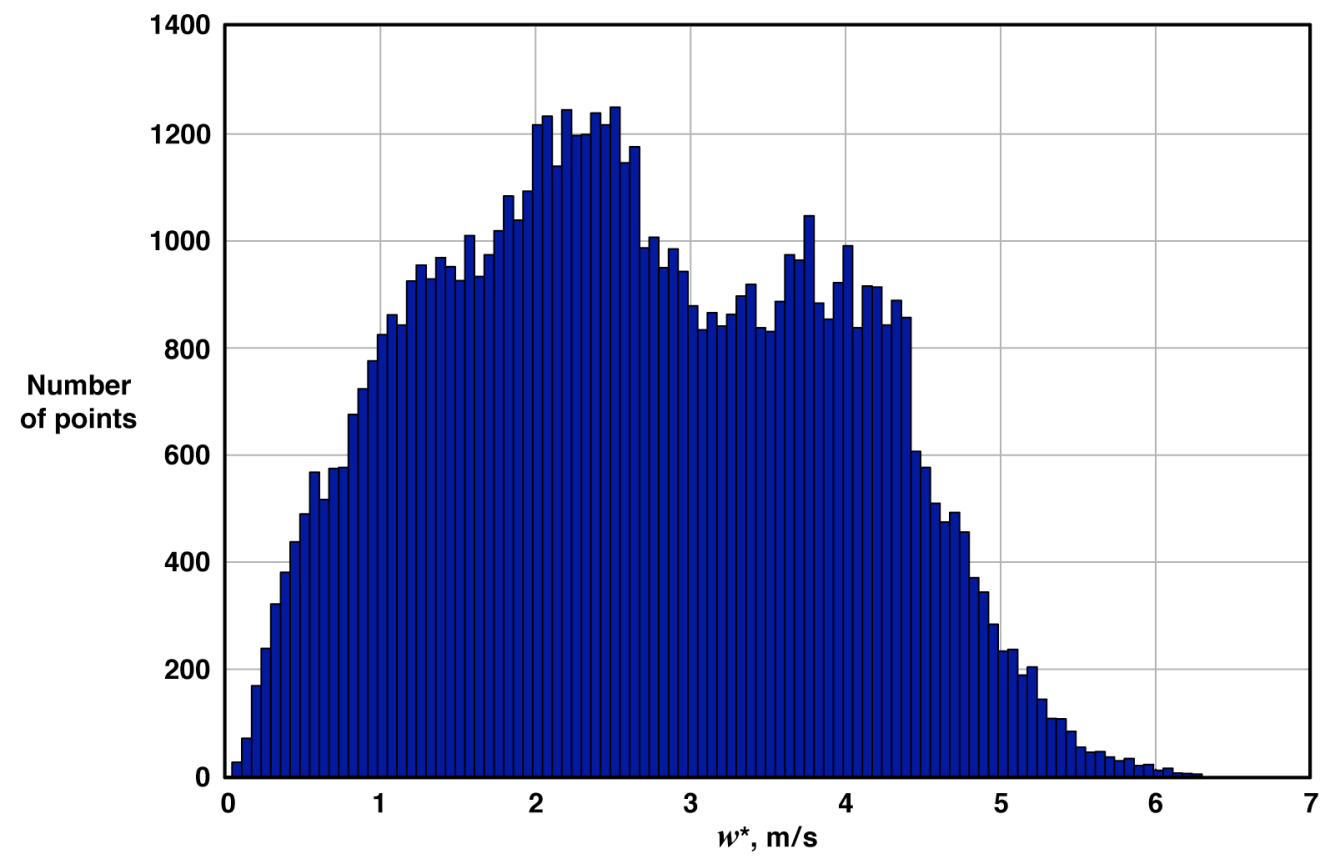

Figure 3. The $w^{*}$ histogram for all samples during daylight hours of 2002, when updrafts were present.

A statistical representation of $w^{*}$ was found using percentiles. The following percentiles were chosen as test points: $2.3,15.9,50.0,84.1$, and 97.7. The five test cases are referred to as $-2 \sigma,-1 \sigma$, mean, $+1 \sigma$, and $+2 \sigma$ because they are analogous to the standard deviation and mean values of a Gaussian probability density function (PDF). The use of percentiles allowed the calculation of a simple set of test cases to represent the distribution of convective velocity scale.

A distribution of all $z_{i}$ values for each selected $w^{*}$ in the test point matrix was created by collecting all $z_{i}$ points corresponding to $w^{*}$ values that fell within a window of $\pm 0.1 \mathrm{~m} / \mathrm{s}$ from the selected test point $w^{*}$. Figure 4 shows an example of the $z_{i}$ data selection for a given $w^{*}$. A Gamma PDF was used to model the statistics of $z_{i}$. The Gamma PDF coefficients that best fit the data were used to calculate the $-1 \sigma$, mean, and $+1 \sigma$ points in the test point matrix. Table 1 gives the resulting set of convective scale factor test points. 


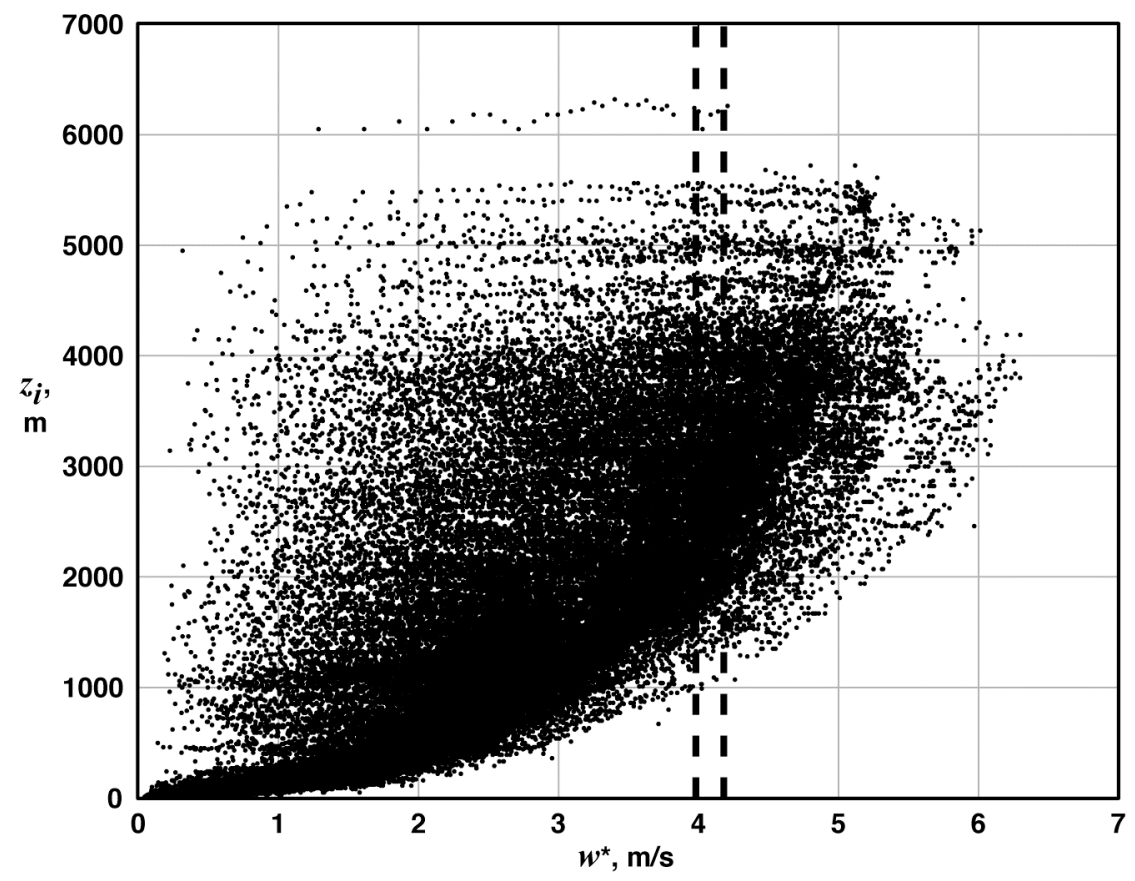

Figure 4. Convective mixing-layer thickness, $z_{i}$, as function of convective velocity scale, $w^{*}$. (Dashed lines indicate $z_{i}$ window for the example case of $w^{*}=4.08 \mathrm{~m} / \mathrm{s}$.)

Table 1. Convective scale test points during times when updrafts are present.

\begin{tabular}{lcccc}
\hline \hline \multicolumn{1}{c}{ Description } & $w^{*}, \mathrm{~m} / \mathrm{s}$ & $-1 \sigma z_{i}, \mathrm{~m}$ & mean $z_{i}, \mathrm{~m}$ & $+1 \sigma z_{i}, \mathrm{~m}$ \\
\hline$-2 \sigma w^{*}$ & 0.46 & 25.6 & 53.6 & 97.4 \\
$-1 \sigma w^{*}$ & 1.27 & 150 & 210 & 1007 \\
mean $w^{*}$ & 2.56 & 767 & 1401 & 2319 \\
$+1 \sigma w^{*}$ & 4.08 & 2134 & 2819 & 3638 \\
$+2 \sigma w^{*}$ & 5.02 & 2913 & 3647 & 4495
\end{tabular}

The test conditions given in Table 1 indicate the year-round statistical properties of convective lift during times when updrafts were present. These test points include variations in convection as a result of time of day and time of year. Table 1 shows large variations of $w^{*}$ and $z_{i}$, illustrating the challenge presented to a soaring aircraft that must use as many updraft sizes and strengths as possible.

Table 2 presents monthly trends. These points represent the mean and maximum values of $w^{*}$ during the daylight hours of the selected month. The $z_{i}$ test points in Table 2 were found by taking the mean of all $z_{i}$ points in the selected month that fell within a window of $\pm 0.1 \mathrm{~m} / \mathrm{s}$ from the selected test point $w^{*}$. Test points given in Table 2 reveal the seasonal variations in updraft strength and altitude. Daily variations are generally sinusoidal, with zero $w^{*}$ at sunrise, maximum $w^{*}$ near noon, and zero $w^{*}$ at sunset. 
Table 2. Monthly convective scale test points for all times between sunrise and sunset.

\begin{tabular}{lcccccccccccc}
\hline \hline & Jan & Feb & Mar & Apr & May & Jun & Jul & Aug & Sep & Oct & Nov & Dec \\
\hline mean $w^{*}, \mathrm{~m} / \mathrm{s}$ & 1.14 & 1.48 & 1.64 & 1.97 & 2.53 & 2.38 & 2.69 & 2.44 & 2.25 & 1.79 & 1.31 & 1.26 \\
$z_{i}$ for mean $w^{*}, \mathrm{~m}$ & 504 & 666 & 851 & 1213 & 1887 & 1728 & 1975 & 1755 & 1382 & 893 & 627 & 441 \\
$\max w^{*}, \mathrm{~m} / \mathrm{s}$ & 3.59 & 3.97 & 4.89 & 5.53 & 5.49 & 5.51 & 6.30 & 5.64 & 5.97 & 4.57 & 4.55 & 4.11 \\
$z_{i}$ for $\max w^{*}, \mathrm{~m}$ & 1800 & 1970 & 3900 & 2380 & 3833 & 4027 & 3962 & 4940 & 2460 & 3285 & 1783 & 1680 \\
\hline
\end{tabular}

\section{Updraft Calculations}

Each $w^{*}$ and $z_{i}$ scaling parameter given in Table 1 and Table 2 can be used to calculate updraft velocity, radius, and vertical velocity distribution using the equations provided in this section. Equation (11) taken from Lenschow ${ }^{10}$ calculates average updraft velocity using height, $z$, and the convective-layer scale parameters, $w^{*}$ and $z_{i}$, from Table 1 or Table 2.

$$
\bar{w}=w^{*}\left(\frac{z}{z_{i}}\right)^{\frac{1}{3}}\left(1-1.1 \frac{z}{z_{i}}\right)
$$

Figure 5 is a plot of Eq. (11). The maximum vertical velocity of $0.45 w^{*}$ occurs at a height ratio, $z / z_{\mathrm{i}}$, of approximately 0.25 . Also note that the updraft velocity is negative for height ratios greater than 0.9 . The height at which peak vertical velocity occurs is lower than those published by Bradbury. ${ }^{11}$ The dissimilarities may occur because of differing climate, topography, or definition of the convective mixing-layer thickness.

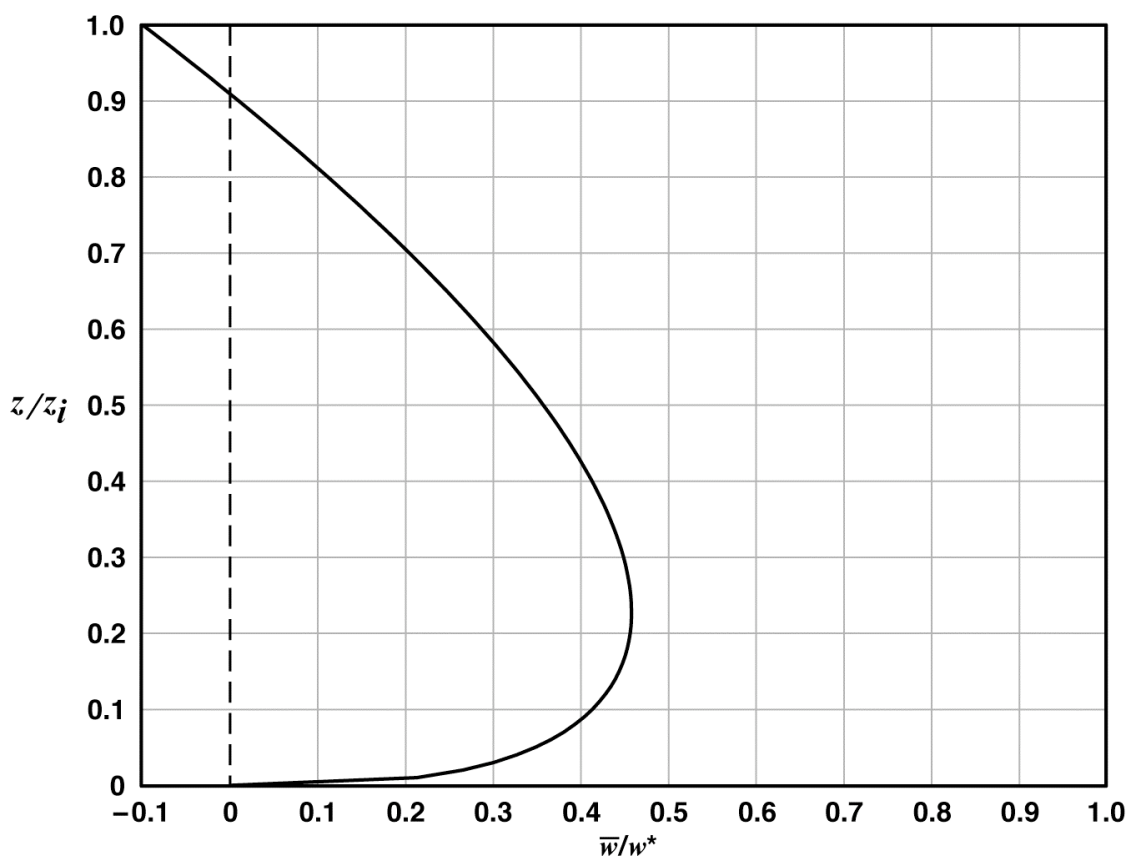

Figure 5. Updraft mean vertical velocity ratio as function of height ratio. 
Equation (12) calculates updraft outer radius, $r_{2}$, as determined by Lenschow. ${ }^{10}$

$$
r_{2}=\max \left(10,0.102\left(\frac{z}{z_{i}}\right)^{\frac{1}{3}}\left(1-0.25 \frac{z}{z_{i}}\right) * z_{i}\right)
$$

Equation (12) predicts small updraft outer radius near the ground and an increasingly larger updraft radius as height increases. Figure 6 shows updraft outer radius ratio, $r_{2} / z_{i}$. Updraft radius is independent of velocity in this model.

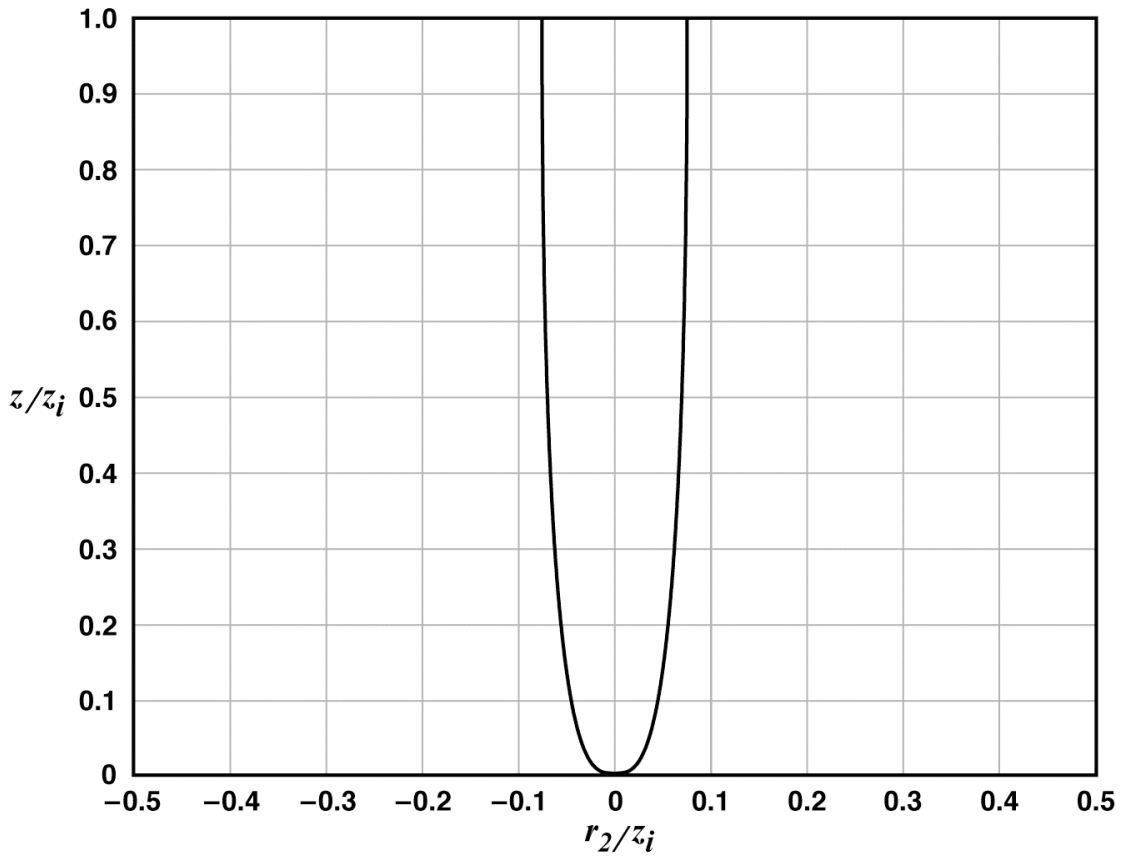

Figure 6. Ratio of outer radius to convective mixing-layer thickness, $r_{2} / z_{i}$, as function of height ratio, $z / z_{i}$.

The distribution of vertical velocity within the updraft varies considerably between updrafts. The literature contains various updraft vertical velocity distributions. Wharington ${ }^{7,12}$ used Gaussian-shaped updrafts to study autonomous soaring techniques and Metzger and Hedrick ${ }^{4}$ used simple square-edged lift regions to optimize flight paths for cross-country flight. Many references depict updrafts to be quite random in size and updraft velocity distribution. In the book Cross Country Soaring, ${ }^{13}$ Helmut Reichmann states that thermals are "seldom, if ever, round" and "the thermals that depart from the norm are most likely the norm itself."

Flight test results were used in an attempt to model the distribution of vertical velocity for the updraft model presented in this paper. Flight tests conducted by Konovalov ${ }^{14}$ show two basic vertical velocity profiles, called type- $a$ and type- $b$. Type-a updrafts are strong and have a wide area of nearly constant lift. Type-b updrafts are weaker and have increasingly more lift toward the center. Konovalov also correlated the frequency of occurrence of type-a and type-b updrafts to the updraft diameter. This paper uses Konovalov's data to correlate the vertical velocity distribution of an updraft to its outer radius. Figure 7 shows a revolved trapezoid that was used to fit Konovalov's type-a and type-b updrafts by adjusting the inner radius, $r_{l}$. This study uses a revolved trapezoid because the trapezoid provided a good approximation to the vertical velocity profiles given by Konovalov. A fit of Konovalov's data yields the piecewise function for the updraft radius ratio, $r_{1} / r_{2}$, given in Eq. (13). 


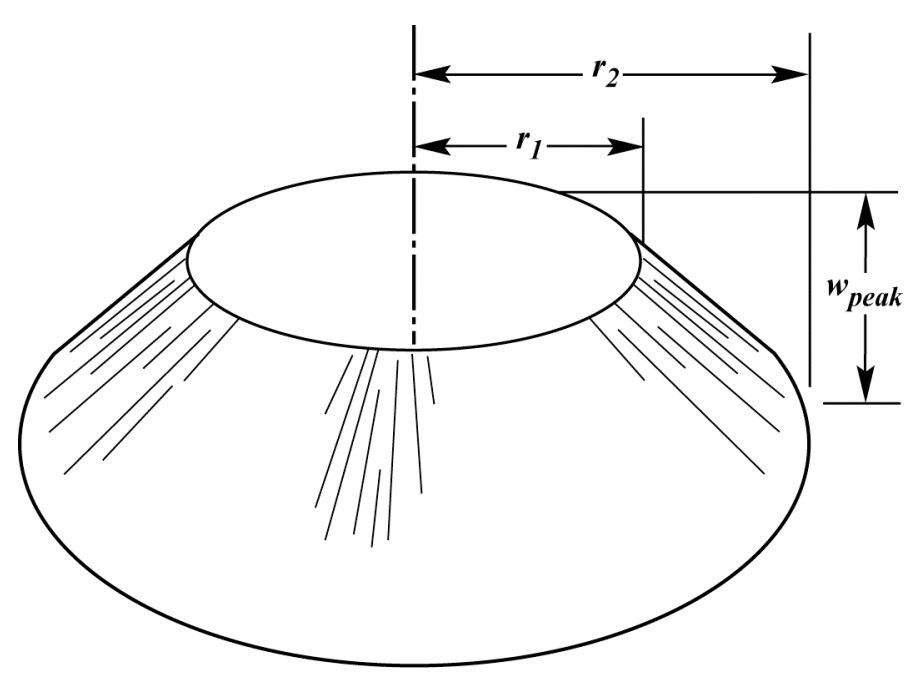

Figure 7. Revolved trapezoid vertical velocity distribution.

$$
\frac{r_{1}}{r_{2}}= \begin{cases}0.0011 * r_{2}+0.14 & \text { for } r_{2}<600 \mathrm{~m} \\ 0.8 & \text { else }\end{cases}
$$

The average vertical velocity of a revolved trapezoid updraft distribution is found by dividing the volume of the revolved trapezoid shape by the base area. Equation (14) gives the resulting relationship.

$$
\bar{w}=\frac{1}{\pi r_{2}^{2}} \int_{0}^{2 \pi}\left[\int_{0}^{r l} w_{\text {peak }} * r * d r+\int_{r 1}^{r 2} \frac{w_{\text {peak }}\left(r_{2}-\mathrm{r}\right)}{r_{2}-r_{1}} r * d r\right] d \psi
$$

Evaluating Eq. (14) and solving for $w_{\text {peak }}$ gives the relationship found in Eq. (15).

$$
w_{\text {peak }}=\frac{3 \bar{w}\left(r_{2}^{3}-r_{2}^{2} r_{1}\right)}{r_{2}^{3}-r_{1}^{3}}
$$

Equation (15) determines the peak value, $w_{\text {peak }}$, of a revolved trapezoid updraft distribution for a given average updraft velocity, $w_{T}$. The vertical velocity distribution was further refined by fitting a bell shape given in Eq. (16) to approximate the revolved trapezoid distribution. A bell shape was chosen because the bell shape defines a smooth vertical velocity distribution.

$$
w=w_{\text {peak }}\left(\frac{1}{1+\left|k_{1} * \frac{r}{r_{2}}+k_{3}\right|^{k_{2}}}+k_{4} * \frac{r}{r_{2}}+w_{D}\right)
$$

In Eq. (16), $k_{1-4}$ are shape constants and $w_{D}$ is the downdraft velocity. This equation describes a family of curves designed to fit the trapezoid shape given by Eq. (13) for a range of discrete $r_{l} / r_{2}$ values. Seven evenly spaced points 
were chosen to represent the range of possible vertical velocity distributions. Table 3 gives the shape constants used in Eq. (16) for each $r_{l} / r_{2}$ ratio. Figure 8 shows the resulting family of updraft velocity distributions. The downdraft velocity term, $w_{D}$, simulates the toroid-like downward velocity found on the outer edge of updrafts as described by Bradbury. Figure 9 illustrates the toroid shape of the updraft as the updraft increases in height. Eqs. (17) and (18) calculate the downdraft velocity.

Table 3. Shape constants for bell-shaped vertical velocity distribution.

\begin{tabular}{ccccc}
\hline \hline$r_{l} / r_{2}$ & $k_{1}$ & $k_{2}$ & $k_{3}$ & $k_{4}$ \\
\hline 0.14 & 1.5352 & 2.5826 & -0.0113 & 0.0008 \\
0.25 & 1.5265 & 3.6054 & -0.0176 & 0.0005 \\
0.36 & 1.4866 & 4.8354 & -0.0320 & 0.0001 \\
0.47 & 1.2042 & 7.7904 & 0.0848 & 0.0001 \\
0.58 & 0.8816 & 13.972 & 0.3404 & 0.0001 \\
0.69 & 0.7067 & 23.994 & 0.5689 & 0.0002 \\
0.80 & 0.6189 & 42.797 & 0.7157 & 0.0001 \\
\hline \hline
\end{tabular}

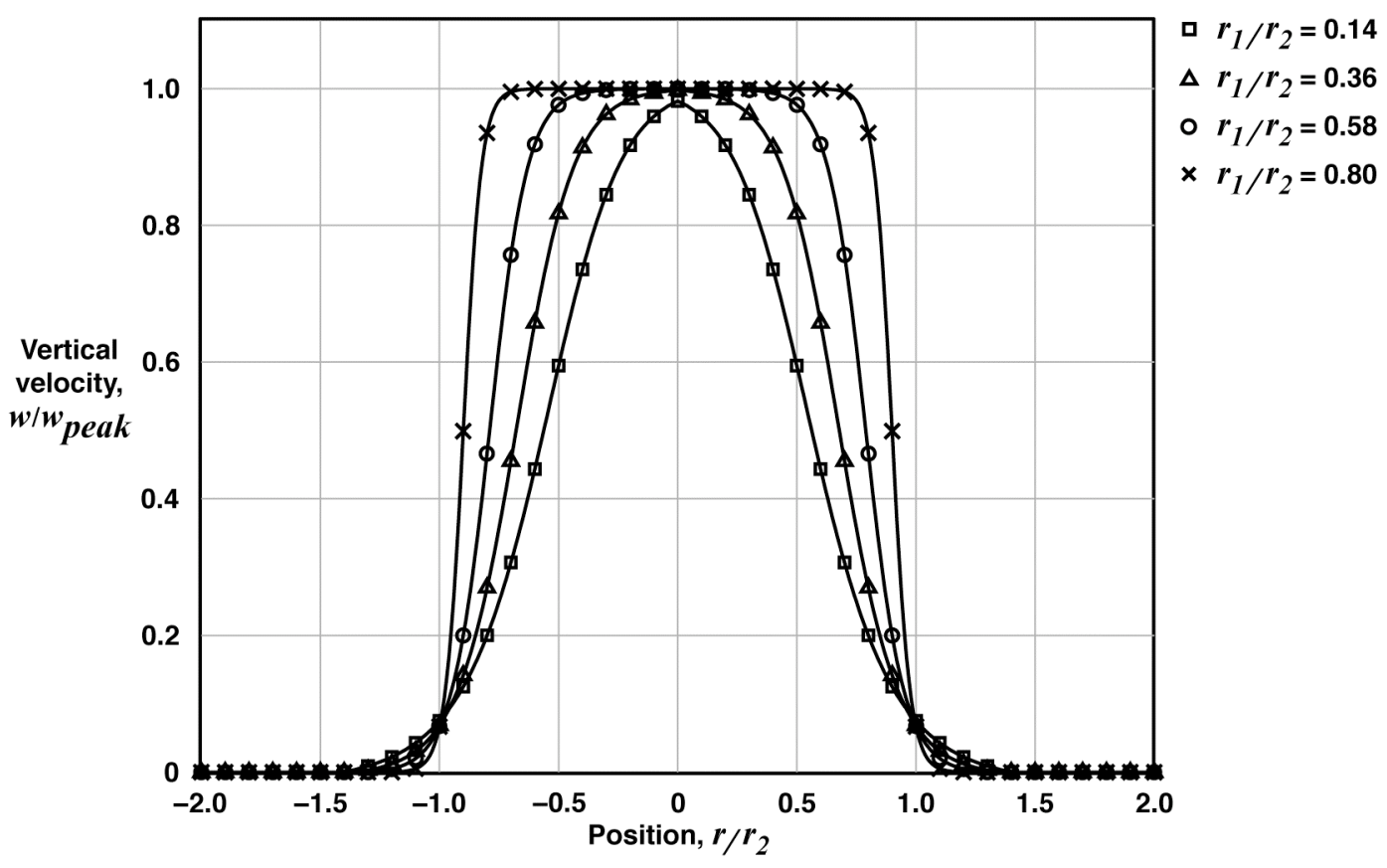

Figure 8. Bell-shaped vertical velocity distributions. 


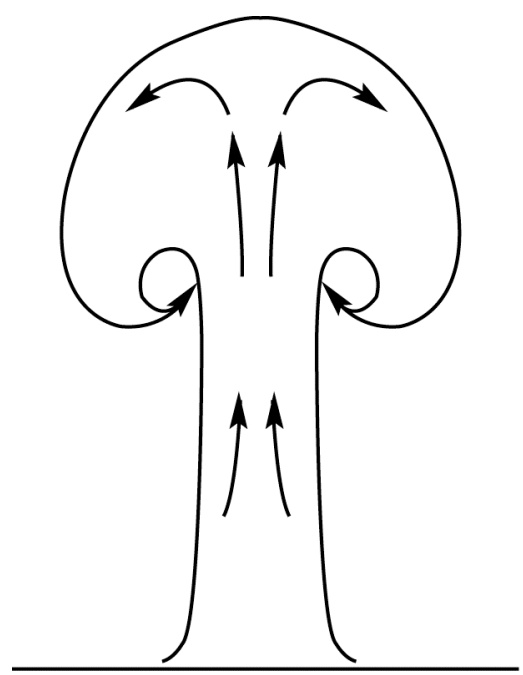

Figure 9. Development of updraft toroid shape as height increases.

$$
\begin{gathered}
w_{1}= \begin{cases}\frac{-\pi}{6} \sin \left(\frac{\pi * r}{r_{2}}\right) & \text { for } r_{1}<r<2 r_{2} \\
0 & \text { else }\end{cases} \\
w_{D}= \begin{cases}2.5 w_{1}\left(\frac{z}{z_{i}}-0.5\right) & \text { for } 0.5<\frac{z}{z_{i}}<0.9 \\
0 & \text { else }\end{cases}
\end{gathered}
$$

Additionally, Eqs. (17) and (18) modify the vertical velocity shape given in Eq. (16) to have zero net vertical velocity when $z / z_{i}=0.9$. The height ratio 0.9 was chosen because the vertical velocity of the updraft is negative at altitudes above 0.9 as given in Eq. (11). Figure 10 gives vertical velocity profiles for low and high updrafts. The vertical velocity profiles show increasing downdraft at the outer edge of the updraft as height is increased. Figure 10 was generated with the convective velocity scale, $w^{*}$, and convective mixing-layer thickness, $z_{i}$, of $2.56 \mathrm{~m} / \mathrm{s}$ and $1401 \mathrm{~m}$, respectively. 


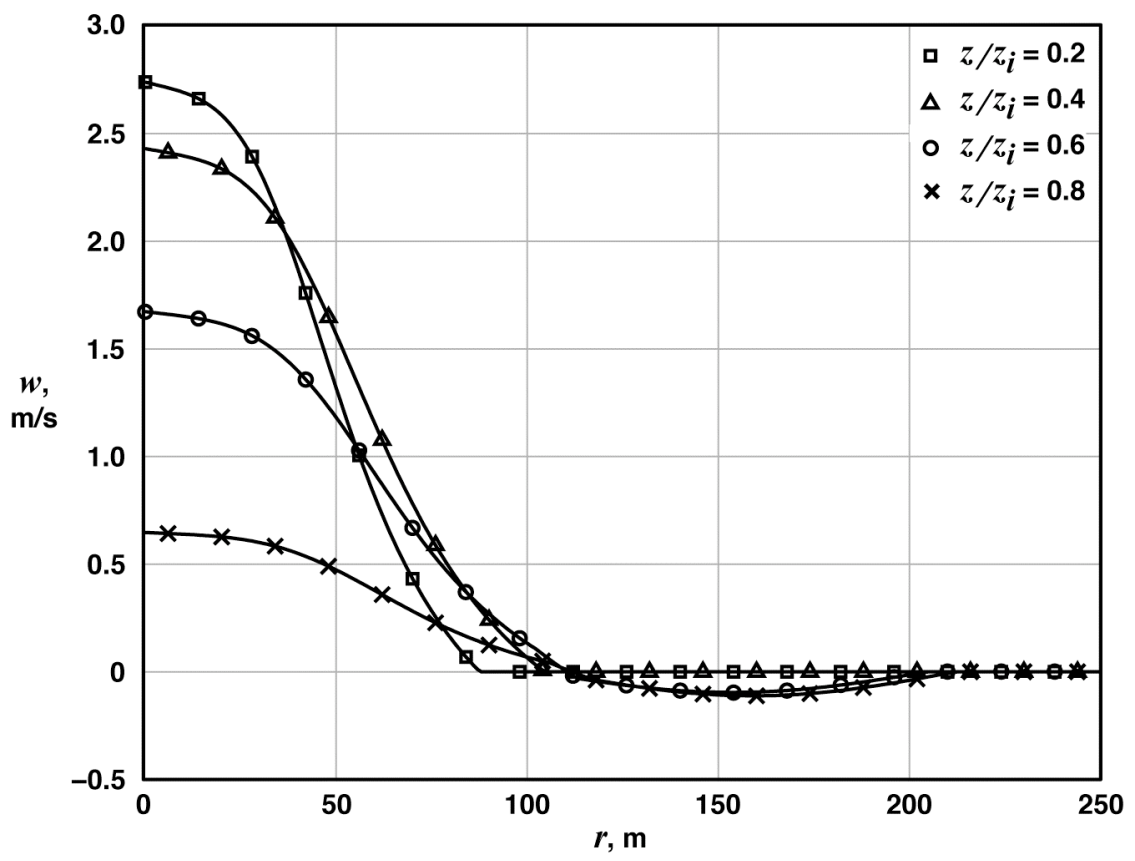

Figure 10. Vertical velocity profiles of a typical updraft with increasing height.

\section{Updraft Spacing and Environment Sink}

Updraft spacing was determined from Lenschow ${ }^{10}$ for a constant $z / z_{i}$ of 0.4 . Equation (19) gives the resulting relationship.

$$
\frac{N_{L} z_{i}}{L}=1.2
$$

In Eq. (19), $N_{L}$ is the number of updrafts encountered along a straight line of length, $L$. Equation (20) solves for the number of updrafts within a given area of length, $X$, and width, $Y$, and a given updraft outer radius, $r_{2}$.

$$
N=\frac{0.6 Y X}{z_{i} r_{2}}
$$

In a given test area, all upward moving air in the form of updrafts is balanced by an equal amount of downward moving air, known as environment sink, in the surrounding atmosphere. Environment sink is applied whenever the aircraft is not inside an updraft. Conservation of mass was used to determine the environment sink velocity for a given test area. Equation (21) gives the resulting relationship.

$$
w_{e}=\frac{-\bar{w} N \pi r_{2}^{2} s_{w d}}{X * Y-N \pi r_{2}^{2}}
$$

Equation (21) relates the environment sink velocity, $w_{e}$, to the average updraft velocity, $\bar{w}_{T}$, using the downdraft velocity ratio, $s_{w d}$, given in Eq. (22).

$$
s_{w d}=\frac{w_{D}}{w_{1}}
$$


The downdraft velocity ratio is used to modify the environment sink calculation to account for the downward moving air defined in Eqs. (17) and (18). The vertical velocity distribution of the updraft can be blended to match the environment sink at the outer radius of the updraft using Eq. (23).

$$
w_{c}=w\left(1-\frac{w_{e}}{w_{\text {peak }}}\right)+w_{e}
$$

Equation (23) stretches the vertical velocity distribution to maintain the maximum vertical velocity at the center of the updraft while allowing a smooth transition to the environment sink at the outer edge of the updraft.

\section{Application}

This paper presents an updraft model for a specific intention-to use the model during the design and simulation of autonomous soaring UAVs. This section introduces an example set of updraft calculations for a typical simulation case. Appendix A gives a MATLAB ${ }^{\circledR}$ (The MathWorks, Natick, Massachusetts) script for this example. The convective scale factors, $w^{*}$ and $z_{i}$, were taken from the mean values given in Table 1 to be $2.56 \mathrm{~m} / \mathrm{s}$ and $1401 \mathrm{~m}$, respectively, for this example. The height, $z$, used in this example was chosen as $280 \mathrm{~m}$, giving a height ratio, $z / z_{i}$, of 0.2. Calculating the updraft outer radius, $r_{2}$, from Eq. (12) yielded $79.4 \mathrm{~m}$. The number of updrafts in the test area (defined by $X=1000 \mathrm{~m}$ and $Y=1000 \mathrm{~m}$ ) calculated from Eq. (20) was five, using $r_{2}=79.4 \mathrm{~m}$ and $z_{i}=1401 \mathrm{~m}$. The resulting five updrafts can be positioned anywhere within the test area. Updrafts were positioned evenly along a diagonal line in this example for clarity. The vertical velocity of the test area was calculated with Eqs. (11) to (18) and (21) to (23) of this paper for every point within the test area using a grid spacing of $10 \mathrm{~m}$. Figure 11 shows the resulting vertical velocities of the test area. Figure 12 shows the vertical velocity distribution of a single updraft as a check case for the code given in Appendices A and B. Figure 12 of this paper was produced with the MATLAB script given in Appendix A. Electronic copies of this code can be obtained from the author.

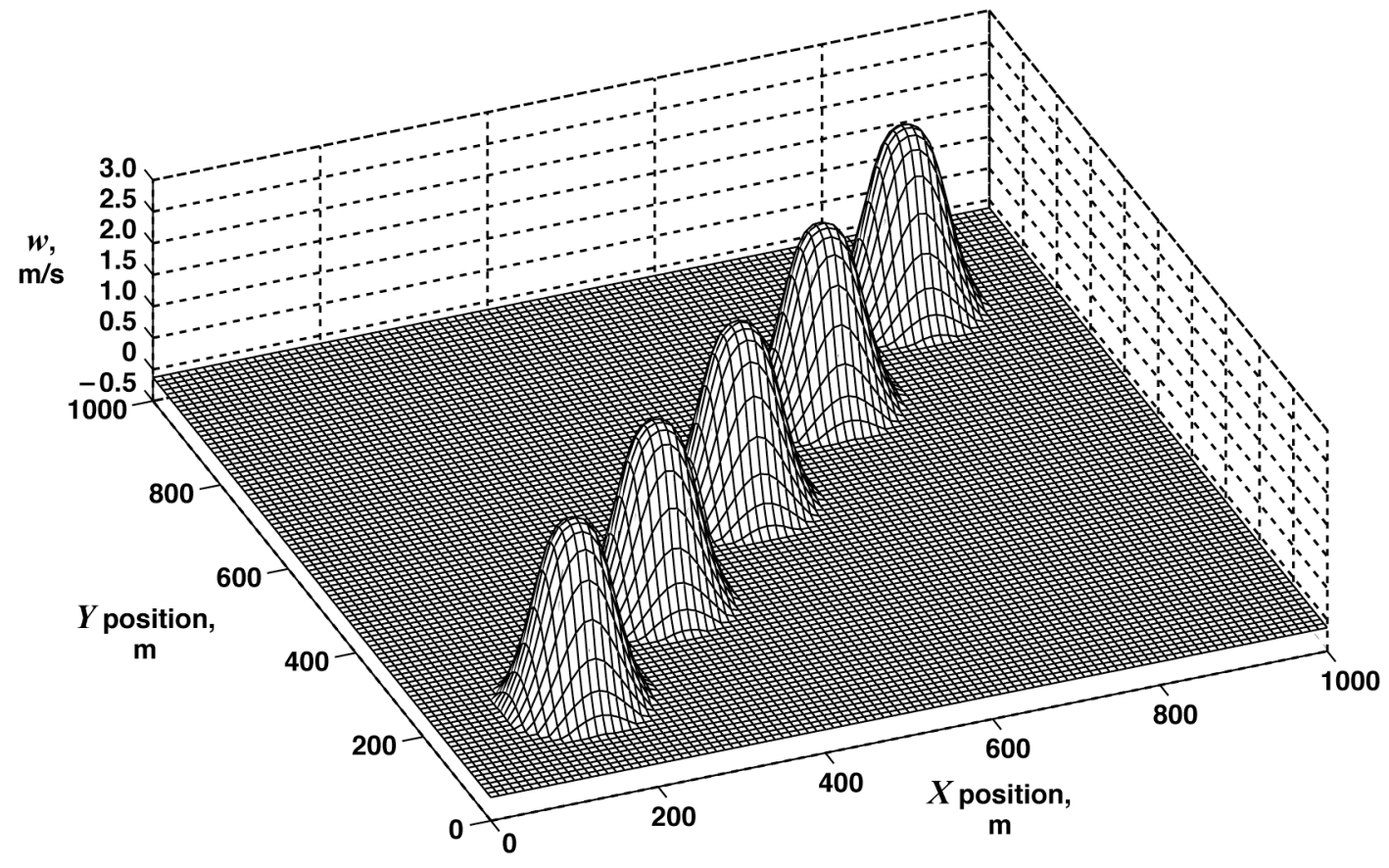

Figure 11. Example test area (calculated from MATLAB code given in Appendix A). Updrafts are positioned along a line for clarity. 


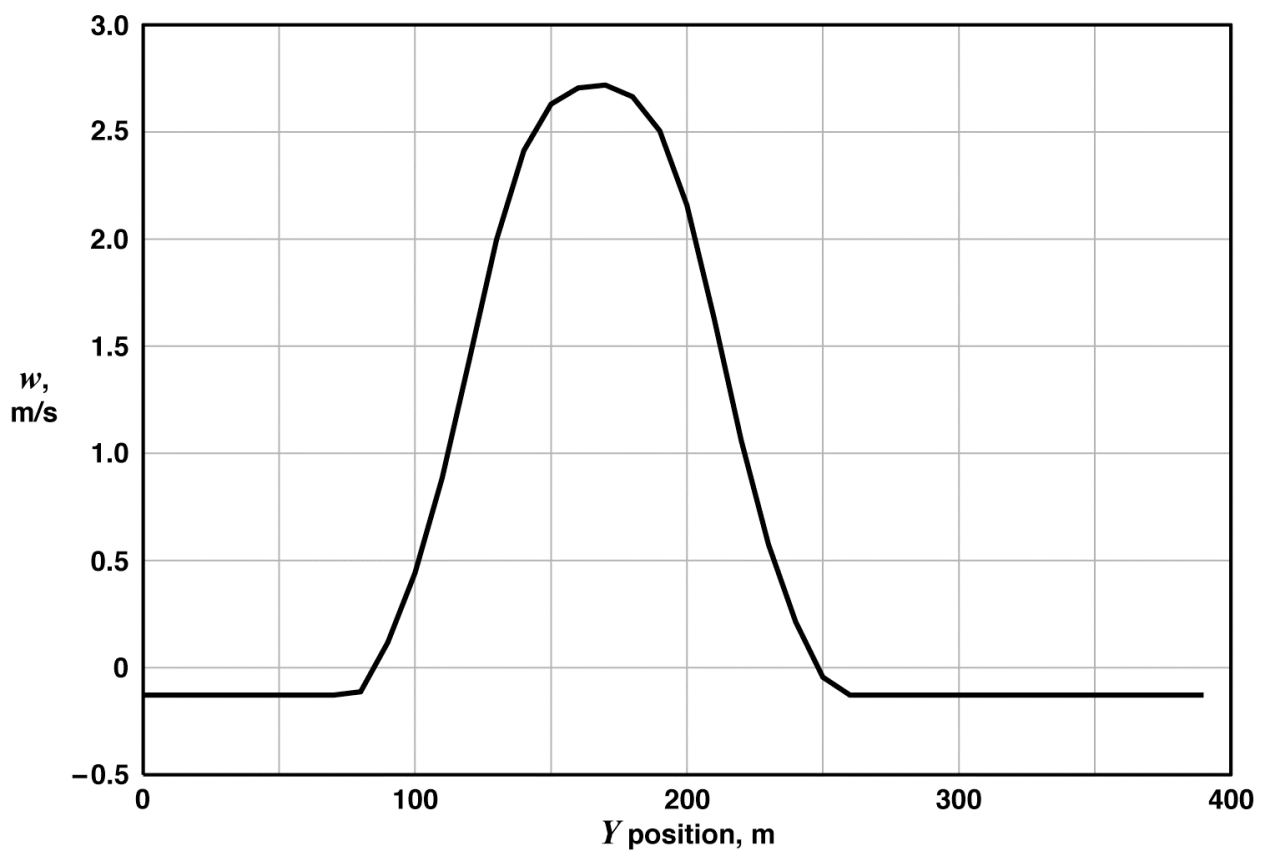

Figure 12. Vertical velocity profile check case (calculated from MATLAB code given in Appendix A).

The updraft positions should be randomly chosen during an actual application. Updraft positions should be held for $20 \mathrm{~min}$ of simulation time and then re-calculated to account for the duration of a typical updraft. Updraft duration can range from 5 to $30 \mathrm{~min}$, indicating that this parameter should be varied during simulation testing of autonomous soaring algorithms.

\section{Future Work}

The updraft model presented in this paper is useful for the development of autonomous soaring guidance and control but does not model all of the significant characteristics of naturally occurring updrafts. Naturally occurring updrafts have time dependant vertical velocities and radiuses. Additionally, naturally occurring updrafts drift and change shape when wind is present; and naturally occurring updrafts merge together to form larger and stronger updrafts as height increases. Downdrafts are also known to form along with updrafts during times of strong convection. Future updraft models, therefore, should include these effects as well as include convective scale parameters for locations and topographies other than the desert.

\section{Concluding Remarks}

This paper presented a model of convective updrafts using convective scale parameters calculated from ground and balloon measurements taken at Desert Rock, Nevada. Convective scale velocity and convective mixing layer thickness test cases were produced using statistical tools. Statistical representation did not include measurement data during times of zero convection, representing 25 percent of the total measurement set. A statistical representation of the convective mixing-layer thickness values corresponding to the set of convective scale velocities was produced by fitting the data to a Gamma probability density function. Convective scale parameters were then used to calculate mean updraft vertical velocity and radius using equations from Lenschow. The vertical velocity distribution within the updraft was calculated by fitting the data in Konovalov to a family of bell-shaped curves. The toroid structure of updrafts as height increases, described in Bradbury, was included in the vertical velocity distribution of this model. Updraft spacing was calculated from a relationship given in Lenschow; and environment sink was calculated using the conservation of mass. This paper also presented an example use of the equations within the paper using the MATLAB code provided in the appendices. Taken together, the equations given herein describe an updraft model that is suitable for the preliminary design and simulation of guidance and control for soaring uninhabited air vehicles. 


\section{Appendix A. MATLAB Code for Example Application}

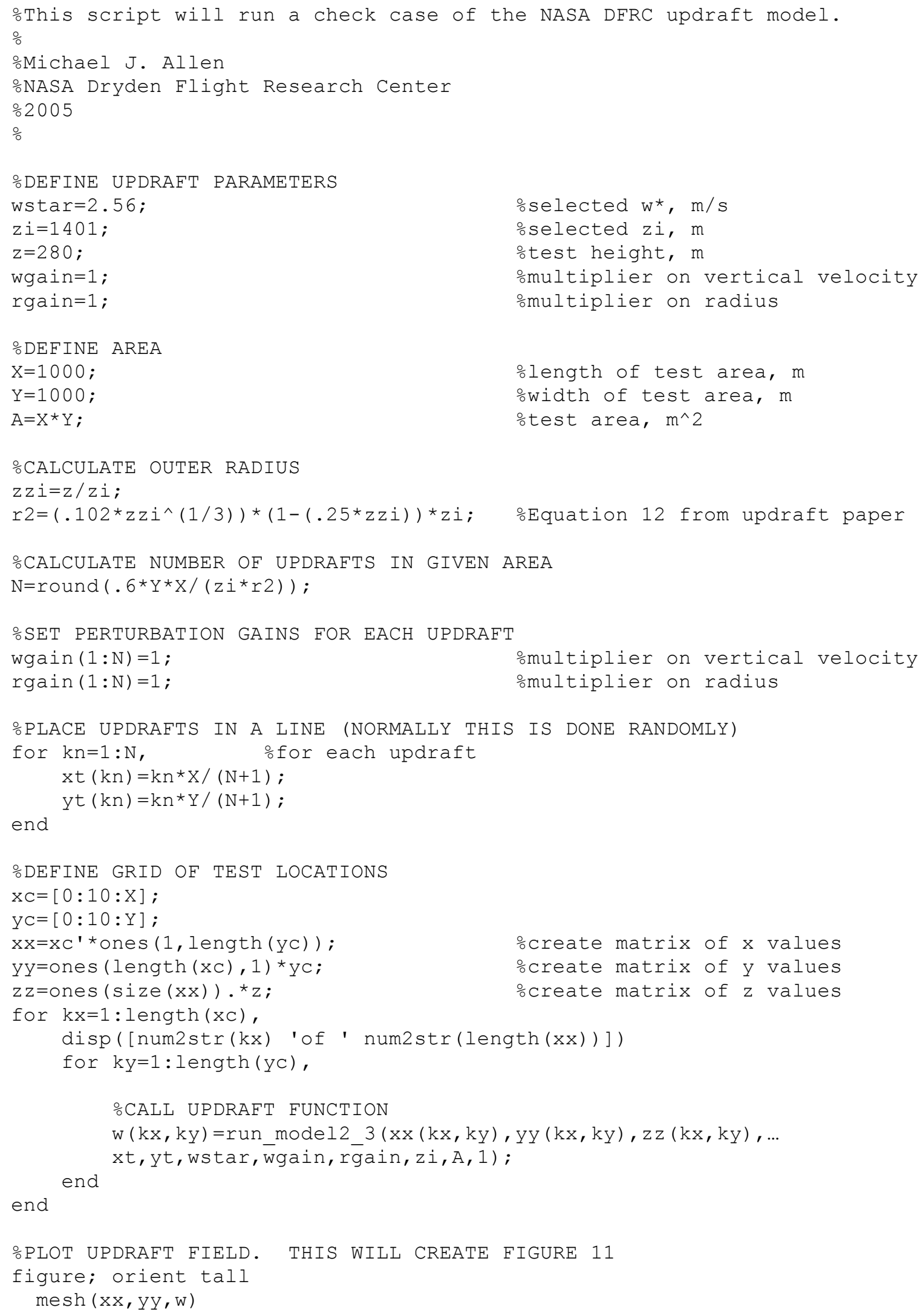




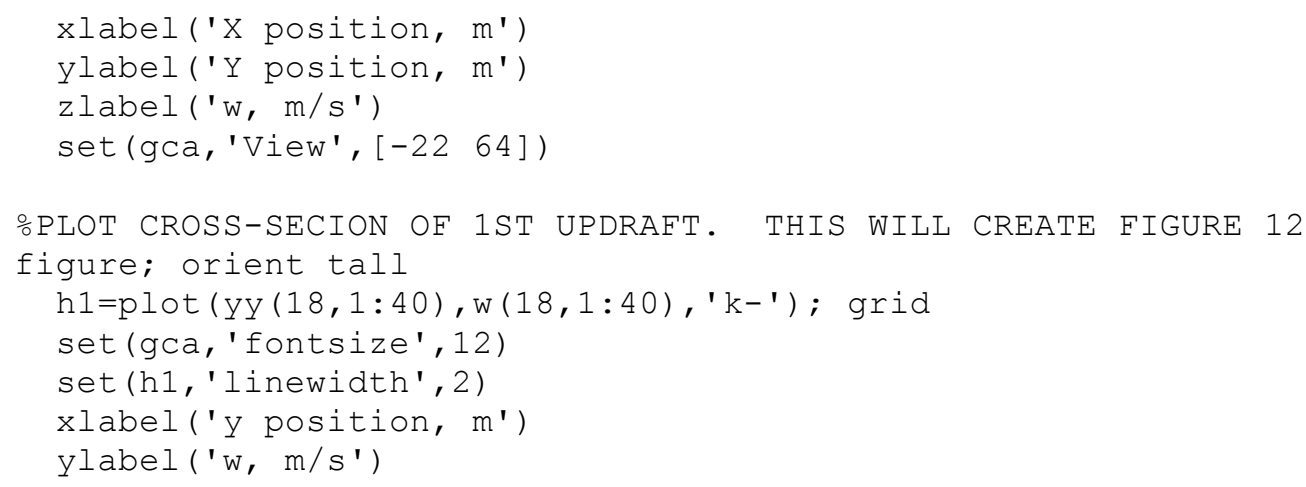

\section{Appendix B. MATLAB Code for Updraft Model}

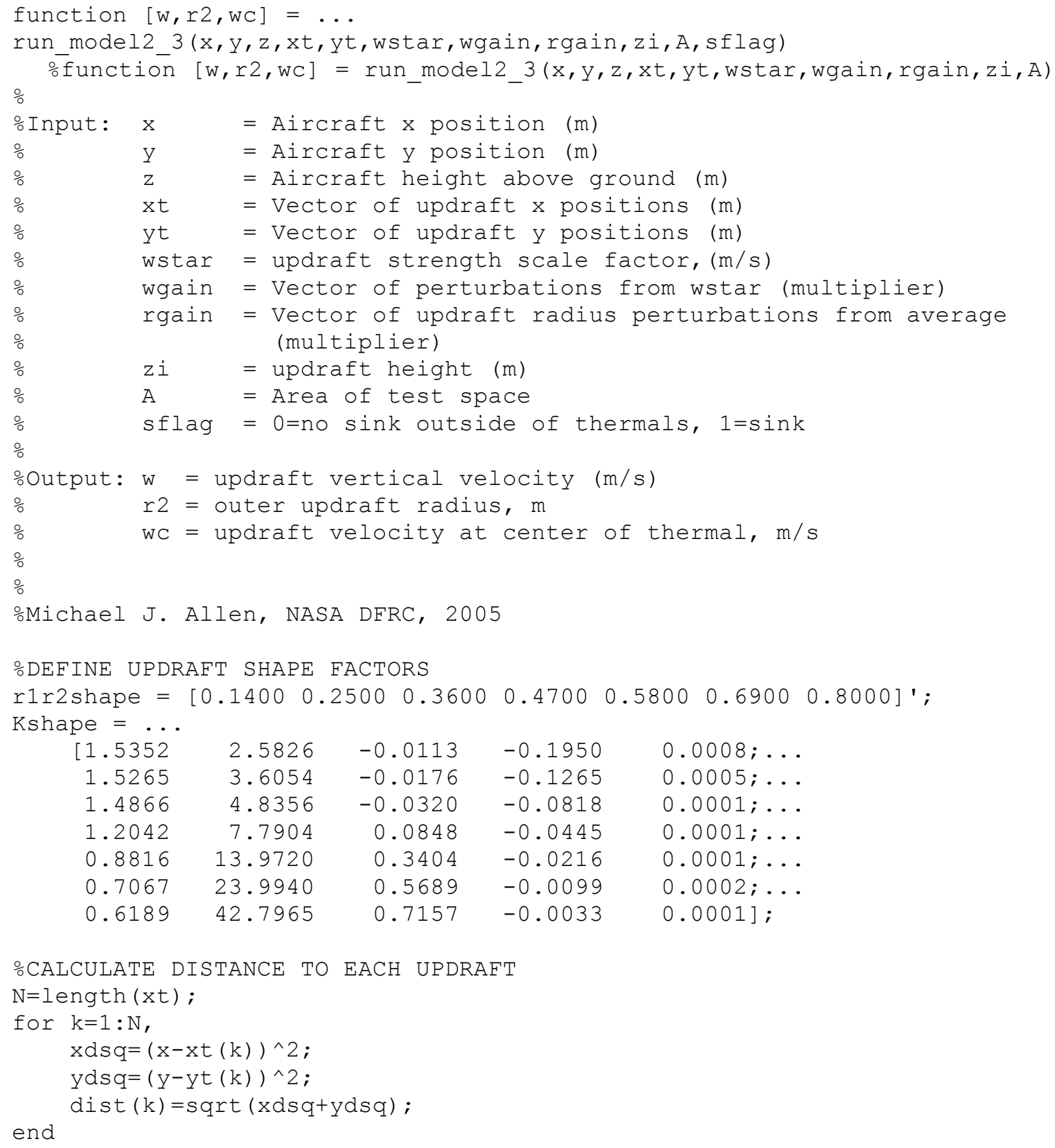




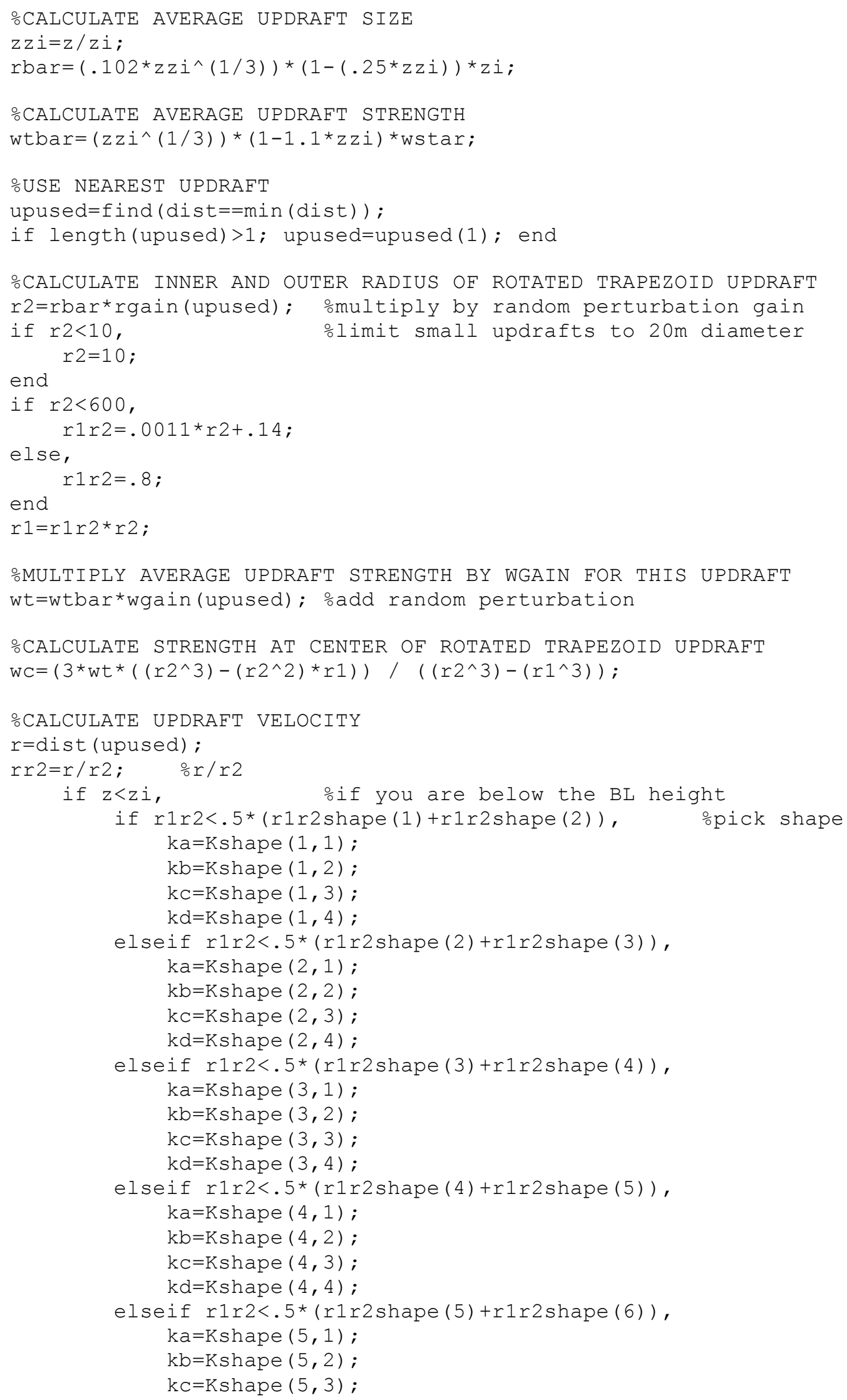




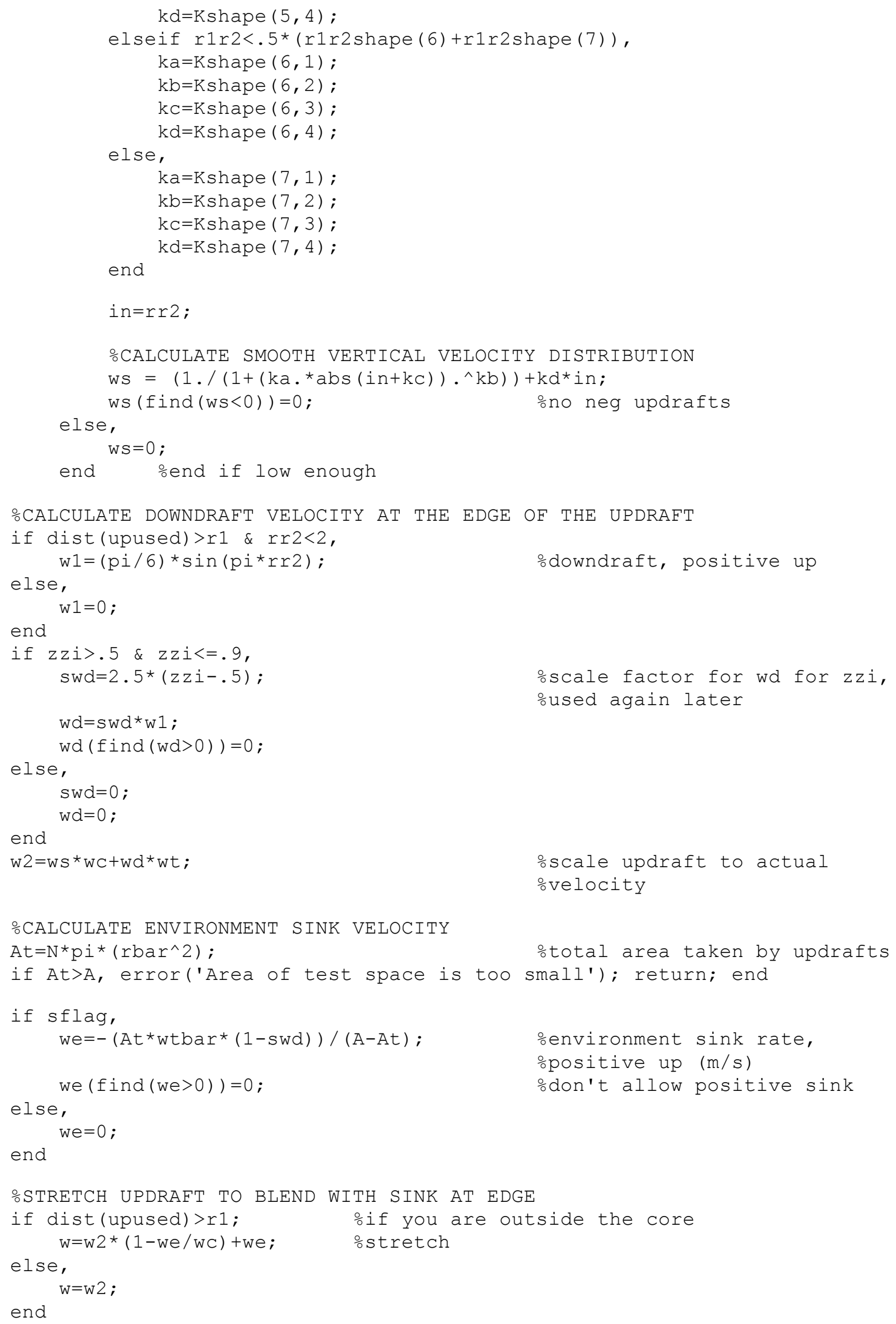




\section{References}

1"Fédération Aéronautique Internationale (FAI) - Gliding World Records," Fédération Aéronautique Internationale, URL: http://records.fai.org/gliding/current.asp?id1=DO\&id2=1 [cited 08 November 2005].

${ }^{2}$ Weimerskirch, Henri, Chastel, Olivier, Barbraud, Christophe, and Tostain, Olivier, "Frigatebirds Ride High on Thermals," Nature, Vol. 421, January 23, 2003, pp. 333-334.

${ }^{3}$ Allen, Michael J. "Autonomous Soaring for Improved Endurance of a Small Uninhabited Air Vehicle," AIAA-2005-1025, 43rd AIAA Aerospace Sciences Meeting, Reno, NV, January 10-13, 2005.

${ }^{4}$ Metzger, Darryl E., and Hedrick, J. Karl, "Optimal Flight Paths for Soaring Flight," AIAA 74-1001, AIAA/MIT/SSA

$2^{\text {nd }}$ International Symposium on the Technology and Science of Low Speed and Motorless Flight, Cambridge, Massachusetts, September 11-13, 1974.

${ }^{5}$ Cone, Clarence D., Jr., "The Design of Sailplanes for Optimum Thermal Soaring Performance,” NASA TN D-2052, 1964.

${ }^{6}$ Mostovoi, Gueorgui V., "Two-Dimensional Lagrangian Model of a Rising Thermal: Application for a Liquid Water Content Spatial Variability of a Warm Cumulus Cloud," Atmospheric Research 43, 1997, pp. 233-252.

${ }^{7}$ Wharington, John, and Herszberg, Israel, "Control of a High Endurance Unmanned Air Vehicle," ICAS-98-3,7,1, AIAA A98-31555, $21^{\text {st }}$ ICAS Congress, Melbourne, Australia, September 13-18, 1998.

"The SURFRAD Network," National Oceanic and Atmospheric Administration, URL: http://www.srrb.noaa.gov/surfrad/index.html [cited 27 September 2004].

${ }^{9}$ Stull, Roland B., An Introduction to Boundary Layer Meteorology, Kluwer Academic Publishers, Norwell, MA, ISBN 90277-2769-4, 1994.

${ }^{10}$ Lenschow, D. H., and Stephens, P. L., "The Role of Thermals in the Convective Boundary Layer," Boundary-Layer Meteorology, 19, 1980, pp. 509-532.

${ }^{11}$ Bradbury, Tom, Meteorology and Flight, A Pilot's Guide to Weather, $3{ }^{\text {rd }}$ Edition, A \& C Black Ltd, London, Great Britain, ISBN 0-7136-4226-2, 2000.

${ }^{12}$ Wharington, John, and Herszberg, Israel, "Optimal Semi-Dynamic Soaring," Royal Melbourne Institute of Technology, Melbourne, Australia, October 11, 1998.

${ }^{13}$ Reichmann, Helmut, Cross Country Soaring, Soaring Society of America, Inc., Hobbs, NM, ISBN 1-883813-01-8, 1993.

${ }^{14}$ Konovalov, D. A., "On the Structure of Thermals," $12^{\text {th }}$ OSTIV Congress, Alpine, USA, 1970. 